\title{
An Interpretative Analysis of Storytelling in the Beverage Industry
}

\author{
By Peter Jones ${ }^{*} \&$ Daphne Comfort ${ }^{*}$
}

\begin{abstract}
Stories, in one form or another, are probably as old as the human race, but in recent years, businesses have increasingly come to recognise the importance of storytelling. The aims of this paper are to explore how the major players in the beverage industry, arguably one of the most important elements in the hospitality industry, have employed stories in their corporate communications and to offer some reflections on current approaches to storytelling within the industry. The findings reveal that all the world's leading beverage companies employ stories on their corporate websites, as part to their approach to business communication, and that these stories address a variety of themes, including company histories, brands, employees' experiences, breweries, customer stories, and corporate social responsibility.
\end{abstract}

Keywords: Stories, Storytelling, Beverage Companies, Hospitality Industry.

\section{Introduction}

Storytelling - simply defined as the cultural and social activity of sharing stories - is probably as old as the human race, but in recent years, there has been increasing recognition of the role of stories in business communication. PricewaterhouseCoopers (2017), for example, suggested that 'storytelling is one of the most powerful tools available to effective communicators' and Gupta (2015) argued that 'stories are an effective tool in the strategy process and for communicating and achieving strategic objectives'. In examining storytelling in business intelligence, Elias et al. (2013), argued that 'stories help us to communicate knowledge, share, and interpret experiences', while in highlighting 'the power of storytelling in public relations' Kent (2015) claimed 'stories have the power to inform, persuade, elicit emotional responses, build support for coalitions and initiatives, and build civil society'. Within the hospitality industry, there has been some interest in the importance and the role of stories and storytelling (e.g. Mossberg 2008, Ryu et al. 2018). That said, Agren and Olund's (2007) suggestion that 'many hotels have a story to share and storytelling is today a buzzword in the industry, but it has not received much attention in the academic world', published over a decade ago still has some force. The beverage industry is arguably one of the most important elements in the hospitality sector of the economy, and the basic research question addressed in this paper is how the major players in the industry are employing storytelling in their corporate communications. The paper then offers a number

\footnotetext{
*Professor, School of Business and Technology, University of Gloucestershire, UK.

${ }^{\dagger}$ Research Associate, School of Business and Technology, University of Gloucestershire, UK.
} 
of concluding reflections on current approaches to storytelling within the beverage industry.

\section{Storytelling and the Hospitality Industry}

Storytelling has its roots in the origins of human civilisation and has traditionally been used to share, and pass on, knowledge, values, myths, legends, fables and religious beliefs, from one generation to another and across geographical space. Initially storytelling was conducted though drawings and word of mouth communication though over time the written, and then the printed, word became an increasingly important storytelling medium. Osman (2014), for example, argued 'transcending barriers of language and culture, storytelling is one of the oldest art forms in history, utilised to transmit cultural, moral and complex information in a simple, engaging and meaningful manner'. More recently, developments in information and communication technologies, particularly social media, have seen storytelling become an increasingly all pervasive and all-embracing experience. Within the business world Gill (2015) defined 'corporate storytelling' as 'the process of developing and delivering an organisation's message by using narration about people, the organisation, the past, visions for the future, social bonding and work itself, in order to create new point-of-view or reinforce an opinion or behaviour'.

Storytelling has certainly assumed increasingly importance within a wide range of businesses and while much of the evidence on the importance of storytelling in business is colloquial and anecdotal, a growing body of academic work has been published on the role of storytelling in business activities and operations. Lundqvist et al. (2013), for example, demonstrated how brand stories can be used to create and reinforce positive brand associations and they suggested that 'more research is needed on the effect of stories on consumer brand responses'. In exploring 'when consumers and brands talk', Woodside et al. (2008) developed a narrative theory that looked to add to storytelling research in consumer psychology by developing narrative theory that described how consumer use brands in the stories they report about themselves. In conclusion, Woodside et al. (2008) suggested that their findings had important implications for marketing practice. In their review of the literature for their study of storytelling practices by Spanish brands, Delgado-Ballester and FernandezSabiote (2016) claimed that storytelling is becoming a persuasive tool in the areas of advertising, communication, branding and management to connect with stakeholders of a company due to its potential effects on story receivers'.

More colloquially, many business commentators and consultants claim a number of benefits for storytelling within the business world. Typically, storytelling is seen to be important in linking a wide range of business challenges and opportunities to everyday human experiences and in helping to generate emotional connections with companies and in giving them a human face. Many good, arguably the best, stories are memorable and thus not only the story itself, but also the message behind the story, can help to sustain 
positive views of a business and its operations and behaviours. Stories can be important in disseminating and sharing a company's values, which may be built on founding philosophies and achievements, and in helping to enhance these values in future business development trajectories. More specifically, stories can be important, in developing awareness and understanding of a company's values and commitments to a wide range of stakeholders and in developing and enhancing brands. Ultimately, and ambitiously, there is the belief that stories can be inspirational and that they can have the power to encourage and stimulate changes in behaviour.

More specifically within the hospitality industry, the role of stories and storytelling has been highlighted, for example, in marketing and in the creating and sharing of experiences. Kennedy (2015) has suggested that 'storytelling' is 'a key to hotel marketing success' while Dickinson (2017) outlined 'how to transform your hotel's marketing with storytelling'. More specifically Dickenson (2017) argued 'by using a storytelling approach in your hotel marketing strategy, you can relate valuable content without actually "selling" your hotel to guests' rather 'you're showing them why they should choose you over your competitors in an engaging, authentic way'. Kennedy (2015) suggested that hotel sales professionals 'should incorporate storytelling into their toolbox of presentation techniques' and should look, for example, to 'tell stories about your area or destination' and to 'talk about how previous guests who have visited for a group or event, later came back to enjoy the hotel for leisure.'

A number of researchers have explored the importance of storytelling in helping to understand tourism and hospitality experiences. Moscardo (2017) for example, drew on work in evolutionary, cognitive and social psychology to reveal that stories play a significant role in supporting positive tourism experiences. In looking to convey 'extraordinary experiences through storytelling', Mossberg (2008) looked at 'conceptualizing tourism and hospitality organisations as stories'. Further she argued that 'for the consumer to be immersed in the story and to have an extraordinary experience, two preconditions are proposed', namely 'the need for the experience to take place in a hedonic service consumption setting' and 'a servicescape that allows the consumer to step away from everyday reality' (Mossberg 2008). Martin and Woodside (2011) used consumers; stories 'to probe how visitors interpret the places, people and situations while travelling in Japan' and suggested hospitality mangers can profitably use such stories to improve service experiences and to design communication strategies to strengthen positive iconic images reported by consumers.

\section{The Importance of the Beverage Industry}

The beverage industry includes manufacturers and distributors of soft drinks, bottled water, energy and sports drinks, milk products coffee and tea, nutritional drinks and beers, wines and spirits. Statista (2019) reported that the volume of the global beverage market had risen from 696 billion litres in 2019 to 948 
billion litres in 2017. The industry is a significant element in the majority of national economies and recent estimates suggest that the global beverage market will be valued at $\$ 1.9$ trillion by 2021 (Research and Markets 2017).

Within the hospitality industry, food and beverages are often grouped together (Dittmer 2001, Novak 2017) but in many ways, beverages are themselves a major element in many hospitality experiences. This is reflected in a number of ways. A wide range of alcoholic and non-alcoholic drinks and a range of bars and lounges are marketed as an important part of the hospitality offer on ocean cruises and all the major cruising companies offer a 'Drinks Package' to customers. Royal Caribbean, for example, has three inclusive beverage packages on offer, including, the Premium Package, at US \$49 per person, per day, which includes house and premium cocktails, frozen cocktails, beers, premium wine by the glass non-alcoholic cocktails, bottled still water, soda fountains with a souvenir Coca-Cola cup and a $20 \%$ discount on wine bottle purchases. All packages have a daily limit on the value of the alcoholic drinks.

In many parts of the world visits to, and tours of, distilleries, vineyards, wineries and breweries are important hospitality experiences. In France, the Bordeaux Tourist Bureau, for example, markets a wide range of wine tours in and around the city while the in Spain the Rioja Alta and Rioja Alavesa Wine Tour offers visitors the opportunity to immerse yourselves in the ancient winemaking traditions of Rioja' (Viator 2019a) and includes visits to three wineries and unlimited wine tastings. In Ireland, Jameson (2019) offers the 'World's Leading Distillery Tour' at the 'iconic birthplace of Jameson Irish Whiskey in Dublin'. The distillery reported 35,000 visitors in 2017 and claims to be the most visited whiskey experience in the world. In Germany the 'Behind-the-Scenes Brewery and Beer Tour in Munich' (Viator 2019b) which includes visits to several of the city's breweries, an opportunity to meet master brewers, to see their beer making facilities, learn about the brewing process and to sample a range of beers. Elsewhere in the world, there are similar tours, for example, Barossa Valley Wineries Tour in Southern Australia, the visit to the Jack Daniels distillery in Tennessee, US, the World of Coca Cola Tour in Atlanta, US and the tour of Labatt's brewery in London, Ontario, Canada.

Within the UK, over 35,000 public houses (pubs) advertise stocking 'real ale', (traditional draught cask beers), as the often-defining feature of their offer. The Cottage Inn at Baltic Wharf on Bristol Harbour offers three locally produced real ales and real cider while he Orchard located nearby sells over 20 still ciders and perries sourced from rural farmhouse producers across the country as well as a selection of real ales. Classic Hospitality, advertises its steam train hospitality packages for the Cheltenham Festival, the pinnacle of the UK's National Hunt Racing Season, with the message 'enhance your steam train journey by pre-ordering a bottle of Champagne which we will have ready on your table or in your private cabin ready for you and your guests' arrival' (Classic Hospitality 2019). This message is illustrated by an image of a tray of glasses of champagne. 


\section{Methodology}

In an attempt to explore how the major players in the beverage industry are employing storytelling in their corporate communications, the world's top ten beverage companies, as measured by turnover and reported in the '2018 Top Food and Beverage Companies (Food Engineering 2018), were selected for study. The companies were PepsiCo, Anheuser-Busch Inbev, The Coca Cola Company, Heineken, Suntory, Asahi, Diageo, Kirin, Molson Coors, and Pernod Ricard. As the leading players in the beverages market, the selected companies might be seen to reflect innovative approach to storytelling in corporate communication. Brief pen pictures of the ten selected companies are provided at following the outline of the method of enquiry adopted by the authors.

The authors conducted an Internet search for information, using the key phrase 'stories and storytelling' and the name of each of the ten selected beverage companies. This search, conducted in March 2019, using Google as the search engine, revealed that all ten of the selected ten beverage companies posted what they explicitly labelled as stories on their corporate websites. A selection of these stories provided the source material for this paper. In selecting the stories, the authors pursued a simple interpretivist, rather than a more structured systematic approach, such as content analysis. The authors believe their impressionistic approach is appropriate in an exploratory paper, which looks to illustrate the ways the leading beverage companies employed stories as part of their business communication processes. Further, the authors included a large number of verbatim quotations, drawn from the corporate websites, in an attempt to capture the details and emotions of the stories as vividly as possible. The specific examples and selected quotations drawn from the stories were used for illustrative purposes, with the principal aim being on reviewing how the selected beverage companies employed storytelling in their corporate messages and not on providing a comparative evaluation of the storytelling process. The paper is based on information that was posted on the Internet, and thus in the public domain, and the authors took the considered view that they did not need to contact the selected beverage companies to obtain formal permission prior to conducting their research.

PepsiCo is a US multinational food and beverage corporation. The company's North American Beverages Division traces its origins back to 1898 when Caleb Bradham, an entrepreneur from North Carolina, created Pepsi Cola and began offering it to his pharmacy customers and its current product range includes carbonated soft drinks, energy drinks, juices and juice drinks and ready to drink teas and coffees. Anheuser-Busch Inbev is a multinational drinks and brewing holdings company based in Leuven, Belgium, and its global brands include Budweiser, Corona and Stella Artois. The Coca Cola Company, a US based multinational corporation, is a manufacture, retailer and marketer of nonalcoholic concentrates and syrups and while it owns over 500 brands it is best known for its flagship Coca Cola drink. Heineken is a Dutch brewing company, it owns some 160 breweries in over 70 countries and produces a wide range of 
beers and ciders and its brands include Heineken, Amstel, Birra Moretti and Cruz Campo.

Suntory is a Japanese brewing and distillery group originally established in Osaka, and it produces a range of alcoholic and soft drinks. Its alcoholic brands include Suntory Whisky, Courvoisier, Gilbeys, Jim Bean and Laphroaig. Asahi is a Japanese beer and soft drinks company based in Tokyo and its brands include Asahi Super Dry, Peroni, Tyskie and Lech. Diageo is a UK based multinational alcoholic beverages company headquartered in London, it produces Smirnoff, Johnny Walker, Baileys and Guinness and owns 37\% of Moet Hennessey, whose brands include Moet Chandon and Veuve Clicquot. Kirin is a Japanese beverage company whose alcoholic brands include Kirin Ichiban Shibori Nama Beer, Kirin Lager and Kirin Nodogoshi Nama and its soft drinks range includes Mets, a range of soda drinks in a variety of fruit flavours. Molson Coors is a multinational brewing company, headquartered in Denver, US. The company's product range spans beers, lagers, malt drinks, wines and spirits and energy drinks and its beer brands include Carling, Coors Light, Caffrey's Irish Ale and Worthington White Shield. Pernod Richard is a French company headquartered in Paris and its brands include Pernod Anise, Absolut, Jameson Irish Whiskey, Chivas Regal and Jacob's Creek wine.

\section{Findings}

The Internet search revealed that the ten leading beverages companies publicly posted a range of stories on their corporate websites. The stories were presented in a narrative format, often illustrated with images, and a number of the selected companies used video clips as part of the storytelling process. The stories covered a number of themes including company histories, brands, employees' experiences, breweries, customer stories, and corporate social responsibility. Company history and development was a common theme in the storytelling process. Under the headline 'Our History', Diageo, for example, told its 'story - from the $17^{\text {th }}$ century to today'. 'The story begins' in 1627 with 'the first record of the Haig family - the oldest family of Scotch Whisky distillers' and includes Arthur Guinness' signing of a 9,000 - year lease on a property in Dublin in 1759 and the beginning of the production of its hallmark black beer and the blending of whiskies by John Walker in Kilmarnock, Scotland in 1820. Moving towards the present day Diageo's stories include the companies' launch of 'DrinkiQ', designed to 'help consumers make more informed choices about drinking, including the decision not to drink' in 2008, the purchase of Mey Icki, the leading spirits producer and distributor in Turkey in 2011, and the acquisition of the Meta Abo Brewery in Ethiopia in 2012.

Molson Coors reported that 'our company's history can be traced back to 1774' and under the banner 'drink in more of our rich history' outlined the company's key developments and acquisitions across four centuries. Readers were invited to 'Meet Our Families', which outlined the stories of John Molson, Adolph Coors and Frederick J. Miller, who all played key roles in the 
company's development. John Molson, for example, founded Canada's oldest brewery on the banks of the Saint Laurence River in Montreal in 1786. Heineken claimed its 'rich history is a fabric that weaves through the company' and that it 'reaches across countries, across time and includes historical events and people whose legacy we still celebrate today.' Heineken's 'stories behind how we have come to be who we are' are told via a series of video clips. In providing 'A snapshot of our history', Asahi claimed 'our history is rich, our stories are varied, and together they make us who we are'.

Under the headline 'How It all Began', in 1898, Suntory claimed 'the spirit of bold ambition is the base of everything we do.' More specifically, the story recounted how Shinjito Toni, the company's founder, 'pushed boundaries even with his very first store in Osaka, which he started with the vision to bring Western-style wines and liquors to Japan.' Further, the story tells how 'in 1923 Shinjito started a whisky business with the vision of creating an authentic Japanese whisky to suit Japanese tastes'. PepsiCo reported that its 'story started with Caleb Bradham, a North Carolina industrialist, who developed the first PepsiCo recipe in the 1880's' and 'registered a patent for the recipe in 1903.' Further, in the same year, Caleb Bradham 'advertised the drink as exhilarating and invigorating' and it 'sold 7, 9698 gallons' and 'encouraged by the popularity, he collaborated with two investors to bottle Pepsi in 1905'.

A number of the leading beverage companies used to stories to contribute to their brands. Anheuser-Busch Inbev, for example, invited readers to 'Discover more about your Favorite Brands'. 'A New Chapter for Camden Town' told of how 'more than 20 years ago, Australian Jasper Cuppaidge missed a plane at Heathrow Airport on his way home from a surfing trip'. So, the story continued, 'unexpectedly stuck in London, he collected glasses in a local pub for extra cash - and so began a love affair with beer that would result in him founding one of the UK's most prominent modern breweries.' Since then the 'Camden Town Brewery, based in Camden Town, London, has been at the forefront of the British craft-beer movement for years'. In the story 'Innovation at Kona Brewing', Anheuser-Busch Inbev suggested 'the best reason to brew beer in Hawaii is the available selection of fresh, delicious adjunct ingredients. Cacao nibs go into Kona Brewing's Black Sand Porter, while vanilla beans are used to brew Vanilla Thrilla, an imperial vanilla stout. By obtaining these fresh ingredients from farm collectives, Kona can craft a seemingly endless list of new beer recipes - many of which would be prohibitively expensive to replicate anywhere else in the world'.

Diageo told the story of a number of its famous brands. These stories included 'Perfecting the Porter', which outlined how 'precise instructions for brewing Guinness Superior Porter are recorded, laying the foundations of today's Guinness Original and Guinness Extra Stout'. Under the banner 'Smirnoff Revolutionises Vodka', the story is told of how Pytor Smirnoff is credited with developing a method for filtering his vodka through charcoal five times, removing impurities and imparting character'. Other Diageo brand stories focus on John Walker and Sons Old Highland Whisky, Gordons Bronx Cocktail first introduced in 1924 and the launch of Captain Morgan Original 
spiced Rum which pioneered the important role of flavours in the production of rum. The Coca Cola Company posted a number of 'Brand Stories' including 'Orange Vanilla Coke and Orange Vanilla Coke Zero Sugar', which announced that variety-seeking Coca-Cola fans will soon have a new fun-yet-familiar flavor to reach for. Orange Vanilla Coke and Orange Vanilla Coke Zero Sugar - the first Coca-Cola trademark flavor innovations in over a decade' was available in a range of packaging options. Within the story, Kate Carpenter, the company's brand director, claimed 'the team considered three other flavors raspberry, lemon and ginger. But the combination of orange and vanilla emerged as the clear favorite in focus groups', that 'we wanted to bring back positive memories of carefree summer days' and 'that's why we leaned into the orange-vanilla flavor combination - which is reminiscent of the creamy orange popsicles we grew up loving, but in a classically Coke way'.

Employees' stories featured on a number of the leading beverage companies corporate websites. Under the headline 'Great Place to Work: Our Culture Sets Us Apart', Molson Coors, for example, provided three stories of the benefits of working for the company. In 'Your career. Developed here', the company outlined how it offered 'one-on-one mentoring, skill development, career path customization, and leadership coaching. All so we can help you grow your career personally'. The story entitled 'Internationally Mobile' claimed 'as an international brand builder, we believe our people give us a winning edgewhich is why we provide development opportunities all over the world'. In its introduction to 'Our employee stories' Diageo claimed 'we are proud to have a diverse workforce made up of thousands of talented people, each with their own story to tell'. More specifically, Alison king, a liquid scientist, Habtu Bazezuw, a health and safety officer, Lorena Diaz Vargas, a production manager and Alec Begg, a coppersmith, all told their stories via short video clips. In a similar vein, Heineken employed a number of video clips to highlight the stories of some of its employees. The story 'Are You Ready to be Bold', told of how 'tired of being in the office, Marcel dropped his suit and joined the brewing masters in the lab. He helped them to develop ground breaking new flavours'.

The Coca Cola Company posted a large number of customer stories under a series of categories including 'Romance', 'Special Family Times', 'Times with Friends', 'Reminders of Family', and 'Childhood Memories'. All of these stories begin with the lines 'Coca Cola touches the lives of people each and every day. From special occasions to exceptional moments in everyday life, Coca Cola is there.' One of the 'Romance' stories told how 'One winter we had a bad blizzard. I had to have my Diet Coke. My husband traveled our untreated, gravel, snow - and ice covered road 10 miles to town to get my diet Coke. It took him two hours - but he did it for me. This is a testament to a wonderful husband and a fantastic soft drink'. Under 'Reminders of Family' was a story, which ran 'as a child I can remember my father taking me to a Greek restaurant in Zanesville, Ohio. Located inside was an old-time fountain parlor where I had my first handmixed Cherry Coca-Cola. The restaurant has 
long since been gone, but the moment in time of sharing that drink with my dad will last for the rest of my life'.

Three of the leading beverage companies used stories to illustrate their approach to corporate social responsibility. In telling 'Our CSV (Creating Shared Value) Story', Kirin, for example, argued 'The Kirin Group is dedicated to resolving these key social issues: being a responsible alcohol producer, health and well-being, community engagement, and the environment'. At the same time, Kirin claimed 'by addressing these issues with a deep commitment, we will help create a prosperous society and a bright future for our customers.' Further, the company suggested 'to be able to pass on a beautiful planet to future generations is a wish for all of us' and 'as a company that benefits from the many blessings of nature, including water and agricultural products, we recognise that sustainability of the global environment is essential to ensuring the continuity of our business'. Heineken's 'Our Sustainability Story' was told in seven chapters. According to this story, 'minimising the impact of our business from barley to bar and from orchard to glass is a top priority' as is continuing to invest 'in our brewing facilities to modernise and make them more energy efficient'. At the same time, some of the selected companies used stories to outline their approaches to environmental management. The Coca Cola Company, for example, described its endeavours in looking to 'Create a World without Waste' and more specifically in exploring 'ways to make recycling better and more accessible to more places'.

Some of the leading beverage companies posted more novel stories on their corporate websites. In 2018, Pernod Ricard posted four short videos, featuring four scenes played by actor Robert Hoehn about employees' lives, in stand-up comedy style. One of these stories concerned the 'exploit achieved by Ronnie and Steven, two Scottish employees working at the Miltonduff distillery who, armed only with shovels and sand bags defied a true rainstorm to prevent their production site from flooding'. More generally, Pernod Richard argued that 'defined by its creators of conviviality signature' the company had 'transformed its unique culture and its employee pride into a key element of its identity.' Kirin told 'The Story Behind Kirin Beer Labels', which told how 'the kirin depicted on Kirin Beer labels is a legendary creature derived from ancient Chinese myths and is said to be a harbinger of good luck.' Under the headline 'Our Most Beautiful Breweries', Anheuser Busch Inbev told the stories of a number of its breweries including the story of the 'Cerveceria Patagonia Brewery' in Argentina, which overlooks 'the sublime glacial Moreno Lake'. The brewery combines hops from Patagonia, German brewhouse technology and decades of knowledge from master brewers, while 'the attached bar gives visitors the opportunity to try many varieties of local beer and take in the incredible view'. 


\section{Concluding Reflections}

The findings reveal that all the world's leading beverage companies employ stories on their corporate websites, as part to their approach to business communication, though the nature and the extent of storytelling varies between companies. These stories address a variety of themes, including company histories, brands, employees' experiences, breweries, customer stories, and corporate social responsibility. While the stories only provide a snapshot at a particular moment in time, three/four sets of concluding reflections merit attention.

Firstly, while the stories address a variety of themes, they all have a clear corporate stamp, and they were designed to promote and enhance a positive image of beverage companies and of the joys and pleasures associated with the consumption of their products as part of the hospitality experience. Further these stories were specifically choreographed to that end by the beverage companies. As such, these stories stand in marked contrast to a number of different messages about the consumption of alcohol, for example, and about its role in society. While some of the stories posted by the companies that produce and market alcoholic drinks, and the websites on which they are posted, include messages about responsible drinking, views about alcohol consumption are contested. There is also growing political, medical and public concern about excessive alcohol consumption and about its costs and consequences to society. Alcohol Change UK (2018), for example, recognised that 'alcohol is part of many of our lives. We use it for celebration, to socialize, to wind down, to cope' but argued 'yet every year alcohol-related harm leads to thousands of lives lost and hundreds of thousands more damaged. The harm goes far beyond those who drink too much, affecting families, communities and ultimately our whole society'.

Concerns about the positive image stories can promote about the beverage industry are not only confined to alcohol. Soft drinks, including soda, colas, tonics, lemonade and energy drinks, for example, are the largest single source of calories and added sugar in the US diet (Harvard T.H. Chan School of Public Health 2019). In the UK, the British Medical Association (2018) argued that 'sugar-sweetened beverages are a major source of added sugars and are typically high in calories, and low in essential vitamins and minerals'. The British Medical Association (2018) further argued that it is 'deeply concerned that the intake of added sugars by many children and adults in the UK far exceeds recommended levels and there is increasing concern about their role in the development of a range of health conditions'. On an environmental note, in a recent report (Ellen MacArthur Foundation 2019) it was while Coca Cola revealed that the Coca Cola Company produced 3 million tones of plastic packaging in 2017 and that PepsiCo did not disclose the volume of the plastic packaging it produced. While both companies cited their commitments to striving to make $100 \%$ of plastic packaging reusable, recyclable or compostable by 2025 , the report suggests that both companies still have some way to go to achieve this goal. 
Secondly, many of the leading beverage companies recounted stories about their company history and their founders and one of the aims here is to emphasise trust and confidence in beverages whose popular appeal has stood the test of time. As such, the focus is on using stories to develop and enhance relationships with existing and potential customers. More generally, as illustrated earlier in the paper, a number of the leading beverage companies employ stories to develop their brands. In additional to conventional narrative, video has an important role to play and as revealed earlier, some of the leading beverage companies employed video clips as part of their storytelling process. Pera and Viglia (2016) argued 'video storytelling has tremendous power compared to written storytelling as it favours the occurrence of the emotional dimension of consumer relationship experiences transforming individual consumption experiences into collective ones'. Further, Pera and Viglia (2016) suggested 'by building relationships among members, customers are building a relationship with the brand'.

More generally, however, a number of commentators have raised concerns about the increasing use of stories in contributing to branding and here the issue of authenticity looms large. Naidu (2013), for example, argued in business, all your stories must be authentically true' and emphasised 'it's simply not worth the backlash and the damage that can have on your credibility. All it succeeds in doing is giving you a reputation for manufacturing, spinning and inventing stories'. Where beverage companies use employees' stories, ethical concerns may be seen to arise in that colleagues might feel that a refusal to contribute positively to a request to publicly contribute to corporate storytelling could prejudice his/her current employment or future career prospects. At the same time, there is also the issue of differentiation in that branding is widely seen to be offer important opportunities for companies to differentiate themselves from their competitors. However, while the details of the stories posted by the leading beverage companies vary, as illustrated earlier in this paper, in many cases, the underlying messages about the role of drinks within the hospitality experience are similar and this might be seen, in part at least, to undermine the role of storytelling in branding.

Thirdly, some commentators have questioned whether many of the types of stories employed by the leading beverage companies are stories at all. Gearin (2018), for example, suggested that storytelling has become a loaded term' but that when corporate writers 'engage in storytelling it suggests they are operating at a higher level, following in the grand traditions of Homer, Rowling and Spielberg'. Further Gearin (2018) argued 'unfortunately when brands think about telling stories, they feel they need to talk about themselves how we began, what we make, why we do what we do, the story behind the people behind the brand... Yes, these stories can be nicely told and lovingly produced, but they often make the brand look self-obsessed. Worse than that, they're often incredibly boring'. Gearin (2018) concluded that 'it would be great if more corporate storytelling came from a place where businesses were more interesting, useful, relevant, entertaining or just plain helpful.'

In a similar vein, Hammond (2017) argued 'that not only is the term story overused in the world of communication, it is also widely misused.' Hammond 
(2017) argued that in the 'classical oral storytelling tradition' stories 'were never set in stone but forever changing as they were told, influenced by audience reaction and then re-told.' Here Hammond (2017) suggested that the digital environments not only offer 'accelerated interactivity' but 'still echoes the ancient tradition of storytelling by mirroring the importance of the audience in the process. In both instances, and across centuries, the audience and consumers are there to listen, to develop and to share'. A number of the leading beverage companies are using social media in the storytelling process and looking to the future one of the challenges for these companies is to develop an increasingly sophisticated and interactive approach to their storytelling.

By way of a final conclusion, the contribution of this paper has been to offer an exploratory review of the ways in which the major players within the beverage industry are employing storytelling in their corporate communications. The paper not only provides a general picture of the current nature of storytelling within one of the most important sectors of the hospitality industry, and as such helps to fill a gap in the current literature, but it also provides a valuable platform for further and more detailed analysis of the role of storytelling within the industry. At the same time, the authors' wider reflections on the findings suggest that the nature and role of storytelling within the beverage industry are contested and that this too may offer fertile ground for future research amongst the industry's various stakeholders.

\section{References}

Agren M, Olund M (2007) Storytelling: A Study Of Marketing in the Hospitality Industry, Jönköping University. Retrieved from https://bit.ly/2x0alDa . [Accessed 24 February 2019].

Alcohol Change UK (2018) The Alcohol Change Report. Retrieved from https://bit.ly/2w XK9c2. [Accessed 16 April 2019].

British Medical Association (2018) BMA Briefing: A Tax on Sugary Drinks. Retrieved from https://bit.ly/2XTxanC. [Accessed 18 March 2019].

Classic Hospitality (2019) Cheltenham Festival Hospitality and Steam Train Specialists. Retrieved from http://www.classichospitality.co.uk/. [Accessed 24 February 2019].

Delgado-Ballester E, Fernandez-Sabiote E (2016) "Once upon a brand": Storytelling practices by Spanish brands. Spanish Journal of Marketing 2 (2): 115-131.

Dickenson S (2017) How to Transform your Hotel's Marketing with Storytelling. Retrieved from https://www.hospitalitynet.org/opinion/4083890.html. [Accessed 6 April 2018].

Dittmer PR (2001) Dimensions of the Hospitality Industry. New York: John Wiley.

Elias D, Aufarne M-A, Bezerianos A (2013) Storytelling in Visual Analytics for Business Intelligence. In Human-Computer Interaction - INTERACT 2013. Lecture Notes in Computer Science (Volume 8119).

Ellen MacArthur Foundation (2019) New Plastics Economy Global Commitment. Retrieved from https://www.ellenmacarthurfoundation.org/assets/downloads/GCSpring-Report.pdf. [Accessed 18 March 2019]. 
Food Engineering (2018) 2018 Top 100 Food and Beverage Companies. Retrieved from https://foodengineeringmag.com/2018-top-100-food-beverage-companies. [Accessed 12 March 2019].

Gearin P (2018) The Storytelling Myth and how Brands get it so Wrong, Retrieved from https://brandtales.com.au/storytelling-myth-brands-get-wrong/. [Accessed 4 January 2019].

Gill (2015) Why the PR strategy of storytelling improves employee engagement and add value to CSR: An integrated literature review. Public Relations Review 41 (2015): 662-674.

Gupta M (2015) How Strategic Leaders Use Storytelling. Retrieved from https://bit.ly/2H jaGoq. [Accessed 24 October 2017].

Hammond N (2017) The Myth of Storytelling in Marketing and why Brands should Encourage Story Sharing. Retrieved from https://bit.ly/2FL9oT2. [Accessed 4 January 2019].

Harvard T.H. Chan School of Public Health (2019) The Nutrition Source: Sugary Drinks. Retrieved from https://www.hsph.harvard.edu/nutritionsource/healthy-drinks/sugarydrinks/. [Accessed 19 March 2019].

Jameson (2019) Welcome to the World's Leading Distillery Tour. Retrieved from https://www.jamesonwhiskey.com/en-IE/visit-us/jameson-distillery-bow-st/jdbs-ourhome/worlds-leading-distillery-tour. [Accessed 7 March 2019].

Kennedy D (2015) Storytelling a key to hotel marketing success, Retrieved from https://bit.ly/2FdcXls. [Accessed 24 February 2019].

Kent ML (2015) The power of storytelling in public relations: Introducing the 20 master plots. Public Relations Review 41(4): 480-489.

Lundqvist A, Lilijander V, Gummerus J, Van Riel A (2013) The impact of storytelling on consumer brand experience: the case of a firm-originated story. Journal of Brand Management 20(4): 283-297.

Martin D, Woodside AG (2011) Storytelling research on international visitors: Interpreting own experiences in Tokyo. Qualitative Market Research: An International Journal 14(1): 127-154.

Moscardo G (2017) Exploring mindfulness and stories in tourist experiences. International Journal of Culture, Tourism and Hospitality Research 11(2): 111-124.

Mossberg L (2008) Extraordinary experiences through storytelling. Scandinavian Journal of Hospitality and Tourism 8(3):195-210.

Naidu Y (2013) The Three Pitfalls of Storytelling. Retrieved from https://bit.ly/2x0bNFC. [Accessed 4 January 2018].

Novak P (2017) What Are The 4 Segments of the Hospitality Industry. Retrieved from https://www.hospitalitynet.org/opinion/4082318.html. [Accessed 14 June 2019].

Osman K (2014) Telling Tales - Storytelling as a Marketing Technique for the Travel. Tourism and Hospitality Industry. Retrieved from https://bit.ly/2WC6NSa. [Accessed 6 April 2018].

Pera R, Viglia G (2016) Exploring how video digital storytelling builds relationship experiences. Psychology and Marketing 33(12):1142-1150.

PricewaterhouseCoopers (2017) Storytelling in Business. Retrieved from https://bit.ly/ 2F7e9pq. [Accessed 24 October 2017].

Research and Markets (2017) Growth Opportunities in the Global Beverage Market. Retrieved from https://bit.ly/2KmtHuM. [Accessed 14 June 2019].

Ryu K, Lehto XY, Gordon SE, Fu X (2018) Compelling brand storytelling for luxury hotels. International Journal of Hospitality Management 74(2018): 22-29.

Statista (2019) Global beverage market volume from 2009 to 2018. Retrieved from https://bit.ly/2KVSLZc [Accessed 14 June 2014] 
Viator (2019a) Rioja Alta and Rioja Alavesa Wine Tour. Retrieved from https://www.via tor.com/tours/La-Rioja/Rioja-Alta-and-Rioja-Alavesa-Wine-Tour/d26298-45050P1. [Accessed 7 March 2019].

Viator (2019b) Behind-the-Scenes Brewery and Beer Tour in Munich. Retrieved from https://www.viator.com/tours/Munich/Behind-the-Scenes-Brewery-and-Beer-Tourin-Munich/d487-2850BEER. [Accessed 7 March 2019].

Woodside AG, Sood S, Miller KE (2008) When consumers and brands talk: Storytelling theory and research in psychology and marketing. Psychology and Marketing 25(2): 97-145. 